\title{
Espécies novas e notas sobre Nananthidium Moure (Hymenoptera, Apidae, Megachilinae) ${ }^{1}$
}

\author{
Danúncia Urban ${ }^{2}$
}

${ }^{1}$ Contribuição no 1662 do Departamento de Zoologia, Universidade Federal do Paraná.
${ }^{2}$ Departamento de Zoologia, Universidade Federal do Paraná. Caixa Postal 19020, 81531-980 Curitiba-PR, Brasil. Bolsista do CNPq.
urban@ufpr.br

\begin{abstract}
New species and notes on Nananthidium Moure (Hymenoptera, Apidae, Megachilinae). The following species are described and illustrated: Nananthidium fasciatum sp. nov., $N$. flavoalveolatum sp. nov. and $N$. peruvianum sp. nov. from Peru, and N. schlindweini sp. nov. from Brazil. Notes on the variation of the color pattern of $N$. bettyae Moure, 1947 and N. quadrimaculatum (Cockerell, 1927) are given. A key to the females from South American species is presented.
\end{abstract}

KEYWORDS. Anthidiini; neotropical; new species; taxonomy.

\begin{abstract}
RESUMO. Espécies novas e notas sobre Nananthidium Moure (Hymenoptera, Apidae, Megachilinae). São descritas e ilustradas as seguintes espécies: Nananthidium fasciatum sp. nov., $N$. flavoalveolatum sp. nov. e $N$. peruvianum sp. nov. do Peru e, $N$. schlindweini sp. nov. do Brasil. São dadas notas sobre as variações do colorido do tegumento de $N$. bettyae Moure, 1947 e N. quadrimaculatum (Cockerell, 1927). É apresentada uma chave para a identificação das fêmeas das espécies sul-americanas.
\end{abstract}

PALAVRAS-CHAVE. Anthidiini; espécies novas; neotropical; taxonomia.

Nananthidium Moure, 1947 distingue-se dos demais Anthidiini pelo porte pequeno, carena pré-occipital laminada nas genas e pelos alvéolos alongados na base do propódeo; as fêmeas, pelas mandíbulas tridentadas e, os machos, pelas projeções laminadas curtas e achatadas no tergo distal. Urban (1998) fez a revisão do gênero e propôs uma chave para a identificação das espécies, que ocorrem desde o México até o Sul do Brasil.

As medidas que constam nas descrições são dadas em milímetros e os caracteres morfológicos são os comumente usados nas descrições dos Anthidiini. O material-tipo está depositado nas seguintes instituições: Coleção Entomológica Pe. J. S. Moure, Universidade Federal do Paraná, Curitiba (DZUP); Museu de História Natural "Javier Prado", Universidad Nacional Mayor de San Marcos, Lima (MUSM) e Illinois Natural History Survey, Champaign (INHS).

\section{Nananthidium fasciatum sp. nov. Fig. 1}

Diagnose. Fêmea com clípeo amarelo, primeiro ao quinto tergo com faixa amarela, sexto tergo com mácula discal amarela; mesepisternos e metepisternos amarelos na metade dorsal.

Holótipo fêmea. Comprimento aproximado 5,73; comprimento da asa anterior a partir do esclerito costal 4,08; largura da cabeça 1,73. Cor predominante preta. Cabeça com as seguintes áreas amarelas: o clípeo, nódoa supraclipeal muito pequena, menor que $1 / 2$ do diâmetro do ocelo, máculas paroculares até a tangente ocelar inferior, estrias interalveolares finas e curtas, estria pós-ocelar unida às genais, estas muito largas no terço dorsal e estreitas ventralmente. Mesoscuto com máculas laterais amarelas em "J" invertido; axilas e escutelo quase inteiramente amarelos; tégulas castanhas; asas tingidas de castanho, mais escuras na parte anterior; mesepisternos e meterpisternos com a metade dorsal amarela; pernas enegrecidas, os fêmures anteriores e medianos com estria amarela e os posteriores com nódoa arredondada, também amarela, próxima da base; tíbias e tarsos anteriores amarelo-âmbar. Primeiro ao quinto tergo com faixa amarela, mais larga nos flancos dos dois basais, nos demais tergos mais estreitas nos cantos; o sexto com mácula amarela discal.

Mesoscuto com os pontos separados por áreas planas muito estreitas, polidas e com micro-reticulação esparsa; mesepisternos com os espaços planos entre os pontos.

Holótipo fêmea. "PERU, SM [San Martin], Tarapoto / Near River Shilcayo / 0629/7622, 350 masl / 29.III.03 C. Rasmussen" (MUSM).

Comentário. A fêmea dessa espécie difere das espécies conhecidas de Nananthidium por ter faixa amarela do primeiro ao quinto tergo.

\section{Nananthidium flavoalveolatum sp. nov.} Figs. 2 e 5

Diagnose. Fêmea com o tegumento amarelo-pálido na área basal do propódeo, incluindo os alvéolos e a carena pósalveolar, grande parte do clípeo e na metade dorsal dos mesepisternos e metepisternos; tergo basal e do terceiro ao quinto com faixa amarela larga. 
Holótipo fêmea. Comprimento aproximado 5,58; comprimento da asa anterior a partir do esclerito costal 3,92; largura da cabeça 1,70. Tegumento da cabeça preto menos as seguintes partes amarelo-pálidas: quase todo o clípeo, exceto a mácula preta irregular junto ao ramo horizontal da sutura epistomal e faixa apical preta estreita; as máculas paroculares até a tangente ocelar inferior, largas e com a ponta dorsal quase truncada; nódoa discal interalveolar, menor que $1 / 2$ do diâmetro do ocelo; mácula interalveolar incluindo as respectivas carenas e bífida tanto dorsal como ventralmente, as pontas dorsais maiores que as ventrais, estria pós-ocelar contínua com as genais, estas um pouco mais largas na metade dorsal e estreitando muito em direção às mandíbulas. Antenas com o escapo e toda a face dorsal castanhos, a face ventral do pedicelo e dos fagelômeros castanho-amarelada. Mesossoma predominantemente preto, porém amarelo-pálido nas seguintes áreas: os lobos e as áreas dorso-laterais do pronoto; máculas laterais largas em "J" invertido no mesoscuto, as axilas e quase todo o escutelo, este somente com as depressões basais pretas; área basal do propódeo amarelo-pálida incluindo os alvéolos e a carena pós-alveolar, a margem anterior do propódeo finamente enegrecida e com uma pequena projeção mediana, também enegrecida, entre os alvéolos amarelopálidos; a metade dorsal dos mesepisternos e a mácula dorsal dos metepisternos. Tégulas castanhas; asas tingidas de castanho no terço anterior. Pernas predominantemente castanhas, os fêmures anteriores e medianos com estria amarelo-pálida larga ao longo da face ventral e nos posteriores, só na metade distal; tíbias anteriores amarelo-âmbar com mácula castanho-pálida, os basitarsos anteriores amarelados; pernas medianas com nódoa amarela apical nas tíbias, basitarsos com nódoa amarela, demais tarsômeros castanhos; tíbias e tarsos posteriores castanho-escuros. Tergos pretos na base, com faixa marginal castanha um pouco translúcida e faixa amarela larga no primeiro e do terceiro ao quinto, as faixas tão largas como o dobro do diametro do ocelo; no primeiro, quase até a área vertical do tergo; o segundo com faixas laterais também largas, um pouco afastadas da base nos flancos e, uma nódoa amarela pequena no meio do tergo; as faixas do terceiro ao quinto tergo um pouco afastadas da base e mais estreitas nos lados; sexto tergo e os esternos pretos.

Mesoscuto com os pontos separados por áreas planas muito estreitas, polidas e com micro-retículos esparsos; mesepisternos com espaços planos entre os pontos.

Holótipo fêmea. "Peru, Lambayeque Prov. / Lambayeque / 5.III.1981 / M. E. Irwin"; "INHS / Insect Collection / 53.078" (INHS). Parátipos. Com os mesmos dados do holótipo 1 fêmea (INHS) e 1 fêmea (DZUP).

Comentário. Distingue-se das demais espécies de Nananthidium pelo colorido amarelo-pálido dos alvéolos da área basal do propódeo. Um dos parátipos com estria fina amarela no disco do metanoto.

\section{Nananthidium peruvianum sp. nov.}

Fig. 3

Diagnose. Fêmea com o clípeo, área supraclipeal e o sexto tergo pretos, escutelo amarelo com a depressão basal preta; máculas amarelas nos lados dos dois tergos basais e, faixa discal também amarela do terceiro ao quinto tergo; antenas com o escapo amarelo-ferrugíneo nas pontas e em grande parte da face ventral.

Holótipo fêmea. Comprimento aproximado 6,0; comprimento da asa anterior a partir do esclerito costal 4,45; largura da cabeça 1,80. Tegumento predominantemente preto, cabeça com estrias amarelas finas nas paroculares inferiores, ultrapassando a tangente alveolar dorsal e, a estria pós-ocelar muito fina, interrompida no meio e nos lados, até o topo das órbitas. Antenas com o escapo enegrecido dorsalmente, no lado ventral e nas pontas amarelo-ferrugíneo, ventralmente com mácula difusa castanha; pedicelo e dois flagelômeros basais amarelo-ferrugíneos, com uma tonalidade mais escura na parte dorsal, demais flagelômeros enegrecidos dorsalmente e castanhos no lado ventral. Mesoscuto com duas nódoas látero-basais amarelo-escuras; axilas amarelas com área basal preta; escutelo amarelo menos nas depressões basais e na primeira fileira de pontos. Tégulas castanho-enegrecidas, asas tingidas de castanho; pernas anteriores e medianas com os 3 artículos basais enegrecidos, tíbias e tarsos anteriores amarelo-âmbar, as tíbias com mácula dorsal castanho-pálida, tíbias medianas amarelo-acastanhadas com o lado dorsal castanho e os tarsos medianos castanhos; pernas posteriores inteiramente enegrecidas. Tergos pretos com faixa marginal translúcida castanho-amarelada e as seguintes áreas amarelas: máculas látero-dorsais grandes e arredondadas no primeiro, faixas laterais curtas e estreitas no segundo, separadas por distância maior que o dobro do comprimento do escapo; faixa discal estreita do terceiro ao quinto tergo, mais afastada da base nos cantos.

Mesoscuto com os pontos separados por áreas planas muito estreitas, brilhantes, ornadas com micro-reticulação e rúgulas acompanhando parte do contorno dos pontos; mesepisternos com carenas finas delimitando os pontos nas laterais, ventralmente os pontos contornados por espaços planos estreitos, menores que $1 / 4$ do diâmetro dos pontos.

Holótipo fêmea. "PERU, SM [San Martin] San / Antonio de Cumbaza / 0625/7624 400 masl / 12.V.2002, C. Rasmussen / Ex wet riverbank" (MUSM). Parátipos com os mesmos dados do holótipo, 1 fêmea, (MUSM); 1 fêmea (DZUP).

Comentário. Um dos parátipos com faixas basais estreitas amarelo-escuras no mesoscuto, mais finas nos flancos. As fêmeas de $N$. quadrimaculatum, diferem das de $N$. peruvianum sp. nov., pelo escapo inteiramente amarelo-âmbar, máculas amarelas do clípeo e faixas látero-basais amarelas do mesoscuto, um pouco alargadas nos flancos ou até com prolongamento para trás. 


\section{Nananthidium schlindweini sp. nov.}

Figs. 4 e 6

Diagnose. Fêmeas com o clípeo quase inteiramente amarelo; máculas em "J" invertido nos lados do mesoscuto; primeiro tergo com faixa amarela larga nos flancos, muito estreita na área dorsal, junto à carena tergal e com o contorno posterior sinuado; tergo distal preto.

Holótipo fêmea. Comprimento aproximado 5,50; comprimento da asa anterior a partir do esclerito costal 4,20; largura da cabeça 1,79. Tegumento predominante preto. Cabeça com os seguintes desenhos amarelos: quase todo o clípeo, exceto o bordo castanho e uma área preta junto ao ramo transversal da sutura epistomal; máculas paroculares inferiores até os alvéolos, estreitando um pouco dorsalmente e terminando abaixo da tangente ocelar inferior; estrias interalveolares curtas, junto às respectivas carenas; estrias genais largas e levemente tingidas de âmbar, unidas à faixa pós-ocelar amarela e prolongadas até as proximidades das mandíbulas; antenas amarelo-ferrugíneas, com o lado dorsal preto a partir do terceiro flagelômero. Lobos pronotais e áreas látero-dorsais do pronoto amarelo-âmbar; máculas amareloferrugíneas em forma de "J" invertido nos lados do mesoscuto; escutelo e axilas amarelos, o escutelo com a depressão basal preta; mácula amarela nos mesepisternos, junto aos lobos pronotais e mácula dorsal em meia-lua nos metepisternos. Tégulas amarelo-acastanhadas; asas anteriores tingidas de castanho. Pernas anteriores e medianas amarelo-ferrugíneas porém com as coxas, trocanteres e área basal dos fêmures enegrecidos, estria amarelo-escura ao longo dos fêmures anteriores e amarela nos medianos; os fêmures posteriores com nódoa basal amarela. Primeiro tergo com faixa amarela basal, muito larga nos flancos e estreita na parte dorsal do tergo, aí junto à carena tergal e com o contorno posterior sinuado; segundo tergo com máculas amarelas laterais grandes, mais afastadas da base nos flancos e arredondadas posteriormente; terceiro ao quinto tergo com faixa amarela larga, mais estreita nos lados devido a um recorte anterior raso em forma de arco; margem dos tergos finamente castanha. Tergo distal preto.

Mesoscuto com os pontos separados por áreas planas muito estreitas, polidas; mesepisternos com os pontos separados por espaços planos.

Holótipo fêmea. "Igarassu - PE / Ref. [Refúgio Ecológico] C. [Charles] Darwin 18/03/01 Brasil / L. Pierrot Leg.". " 5429 UFPE" "L121 / Ninho CA05" (DZUP). Parátipo com os mesmos dados, 1 fêmea (DZUP).

Comentário. O parátipo com a faixa amarela do tergo basal incompleta, com duas pequenas interrupções dorso-laterais. A fêmea de $N$. fasciatum sp. nov. tem em comum com $N$. schlindweini sp. nov., a faixa amarela completa no primeiro tergo, porém difere por ter faixa amarela também no segundo tergo.

O nome da espécie é uma homenagem ao Dr. Clemens
Schlindwein, Departamento de Botânica, Universidade Federal de Pernambuco.

\section{Notas sobre variações no colorido do tegumento}

Nananthidium bettyae Moure, 1947

Nananthidium bettyae Moure, 1947: 28.

Nananthidium willineri; Urban, 1998: 626 (identificação errônea).

Ao comentar as variações no colorido das fêmeas de $N$. willineri Moure, 1947, por um equívoco, Urban (1998: 626) relacionou espécimes de $N$. bettyae da Bahia, Espírito Santo, Minas Gerais e Mato Grosso com faixa pós-ocelar amarela estreita e bem delimitada e nódoas amarelas na cabeça e no mesossoma. As fêmeas de $N$. willineri não têm manchas amarelas na cabeça nem no mesossoma, pelo contrário, a cabeça é quase inteiramente ferrugínea, incluindo a faixa pósocelar larga e geralmente contínua com as demais áreas dessa mesma cor.

O holótipo de Nananthidium bettyae e a maioria das fêmeas desta espécie têm uma grande mácula amarela no sexto tergo e a área interalveolar inteiramente preta. Entretanto, o reestudo das fêmeas coletadas na Bahia e Espírito Santo levou à constatação de algumas variações. Entre 16 e 21.XI.1970, T. \& C. Elias coletaram 23 fêmeas em Itapina, Espírito Santo. Destas, somente 6 espécimes de $N$. bettyae com o padrão do holótipo, outras 4 com a mácula discal do sexto tergo em parte amarela e em parte acastanhada e uma com máculas amarelo-escuras ocupando uma pequena área discal do tergo. As 12 fêmeas restantes com o sexto tergo inteiramente preto e duas máculas amarelas alongadas na área interalveolar, mais largas que o ocelo mediano, ou muito estreitas e de tamanhos diferentes no mesmo exemplar e, uma das fêmeas com apenas uma nódoa interalveolar amarela.

\section{Nananthidium quadrimaculatum (Cockerell, 1927)}

Dianthidium quadrimaculatum Cockerell, 1927: 8 Nananthidium quadrimaculatum; Urban, 1998: 626.

Foram observadas as seguintes variações no colorido do clípeo em 7 fêmeas coletadas por C. Rasmussen no Peru, San Martin: o clípeo quase inteiramente amarelo, com máculas subapicais amarelas quase triangulares separadas por uma fina estria preta, ou com faixa amarela subapical larga nos flancos e estreita no meio. Também nos mesepisternos foi anotada a presença de uma pequena nódoa amareloacastanhada sem limites definidos, e de área dorsal amareloâmbar, maior que as tégulas. Na maioria dos espécimes os mesepisternos são pretos.

Chave para as fêmeas das espécies sul-americanas de Nananthidium

1. Tergos amarelo-âmbar com faixa amarela larga do terceiro ao quinto; o sexto tergo amarelo. Venezuela; Colômbia . N. analuizae Urban, 1998 

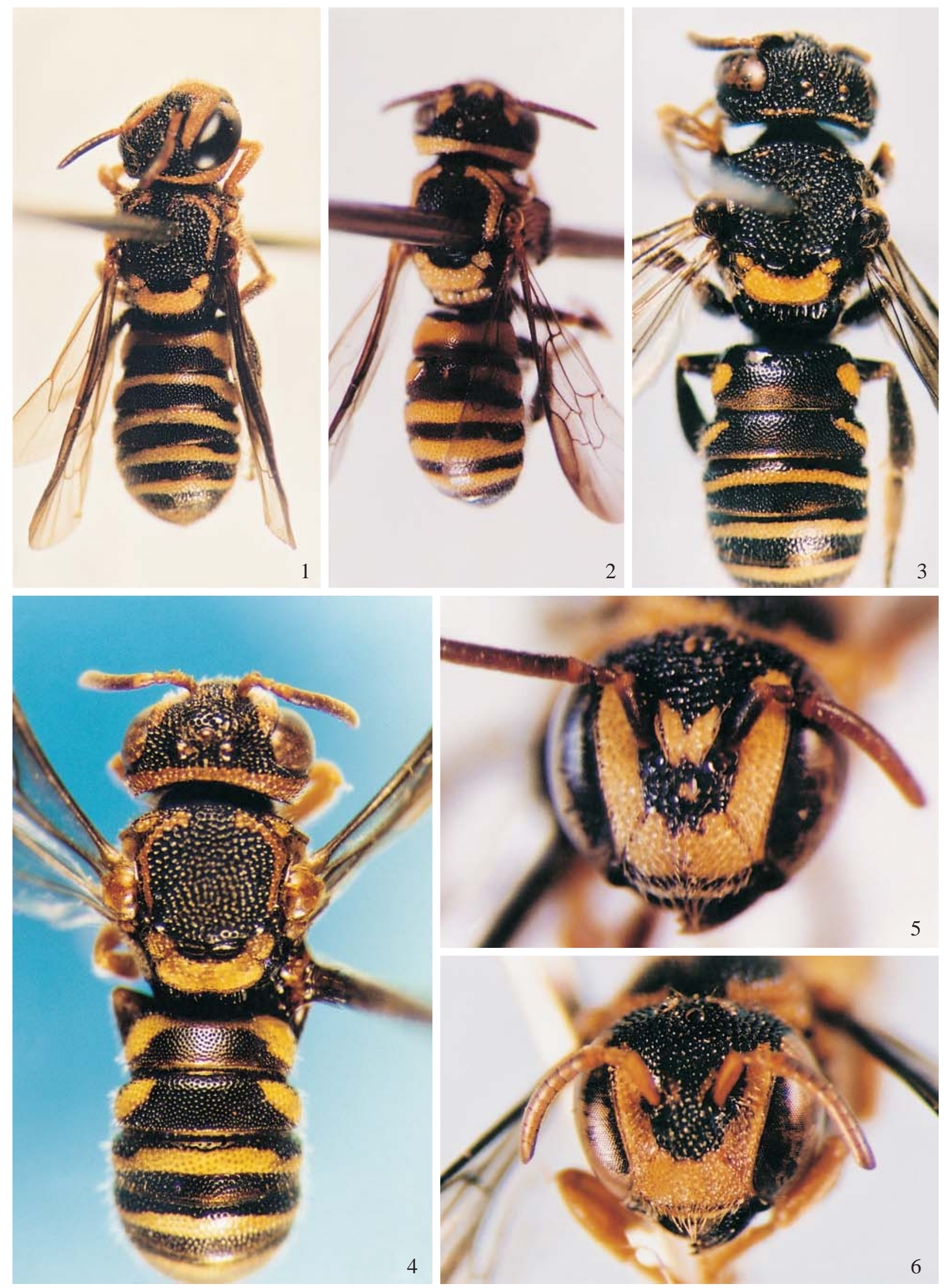

Fig. 1-6. Holótipos de espécies de Nananthidium. (1) N. fasciatum; (2 e 5) N. flavoalveolatum; (3) N. peruvianum; (4 e 6) N. schlindweini. (14) vista dorsal; (5 e 6) cabeça. 
Tergos pretos, com faixa amarela do terceiro ao quinto, ou também nos dois basais; sexto tergo inteiramente preto ou com mácula amarela ... 2

2(1). Tergo basal com faixa amarela, completa ou interrompida

Tergo basal com máculas amarelas laterais e preto na face dorsal

3(2). A faixa amarela do tergo basal muito estreita dorsalmente e com o contorno posterior sinuado; segundo tergo sem faixa amarela completa, com grandes máculas amarelas látero-dorsais; sexto tergo preto. Brasil, Pernambuco N. schlindweini sp. nov.

A faixa amarela do tergo basal não estreitada dorsalmente, o contorno posterior quase reto; segundo tergo com faixa amarela completa; sexto tergo com faixa subapical amarela. Peru, San Martin

N. fasciatum sp. nov.

4(2). Mesossoma com máculas amarelo-ferrugíneas; cabeça com máculas amarelo-ferrugíneas ou quase inteiramente desta cor. Argentina, Salta, Jujuy; Brasil, Mato Grosso; Paraguai, San Estanislao

N. willineri Moure, 1947

Mesossoma com máculas amarelas; cabeça preta com máculas amarelas 5

5(4). Área basal do propódeo com os alvéolos e a carena pósalveolar amarelo-pálidos. Peru, Lambayeque N. flavoalveolatum sp. nov.

Área basal do propódeo inteiramente preta . 6

6(5). Clípeo inteiramente preto, sem nódoas amarelas; mesoscuto com os pontos separados por áreas planas muito finas, brilhantes, com micro-reticulação e rúgulas acompanhando, em parte, o contorno. Peru, San Martin N. peruvianum sp. nov.

Clípeo com nódoas laterais amarelas ou faixa subapical amarela; mesoscuto variável, polido ou com áreas planas finas com micro-reticulação e rúgulas acompanhando o contorno 7

7(6). Mesoscuto com os pontos separados por áreas planas muito estreitas, polidas, raramente com alguma microreticulação; genas com faixa amarela na metade dorsal; Brasil, Bahia, Mato Grosso, Minas Gerais, Espírito Santo, São Paulo, Paraná ..... N . bettyae Moure, 1947

Mesoscuto com os pontos separados por áreas planas muito finas, brilhantes, com micro-reticulação e rúgulas acompanhando, em parte, o contorno; genas com a faixa amarela no terço dorsal. Peru, Huanuco, San Martin; Bolívia, Beni, La Paz; Brasil, Mato Grosso, Rondônia, Acre

N. quadrimaculatum (Cockerell, 1927).

Agradecimentos. Ao Dr. Albino Morimasa Sakakibara, UFPR, pelas fotos que ilustram o trabalho; Dr. Clemens Schlindwein, UFPE; Dr. Gerardo Lamas, Museu de História Natural "Javier Prado", Lima, Peru, pelo material cedido para estudo e ao M. Sc. Claus Rasmussen, Illinois Natural History Survey, Champaign, USA, pelo empréstimo de espécimes.

\section{REFERÊNCIA}

Urban, D., 1998. Notas taxonômicas e espécies novas de Nananthidium Moure e descrição do macho de Bothranthidium Moure (Hymenoptera, Megachilidae). Revista brasileira de Zoologia 15: $621-632$. 